\title{
Human Ovary
}

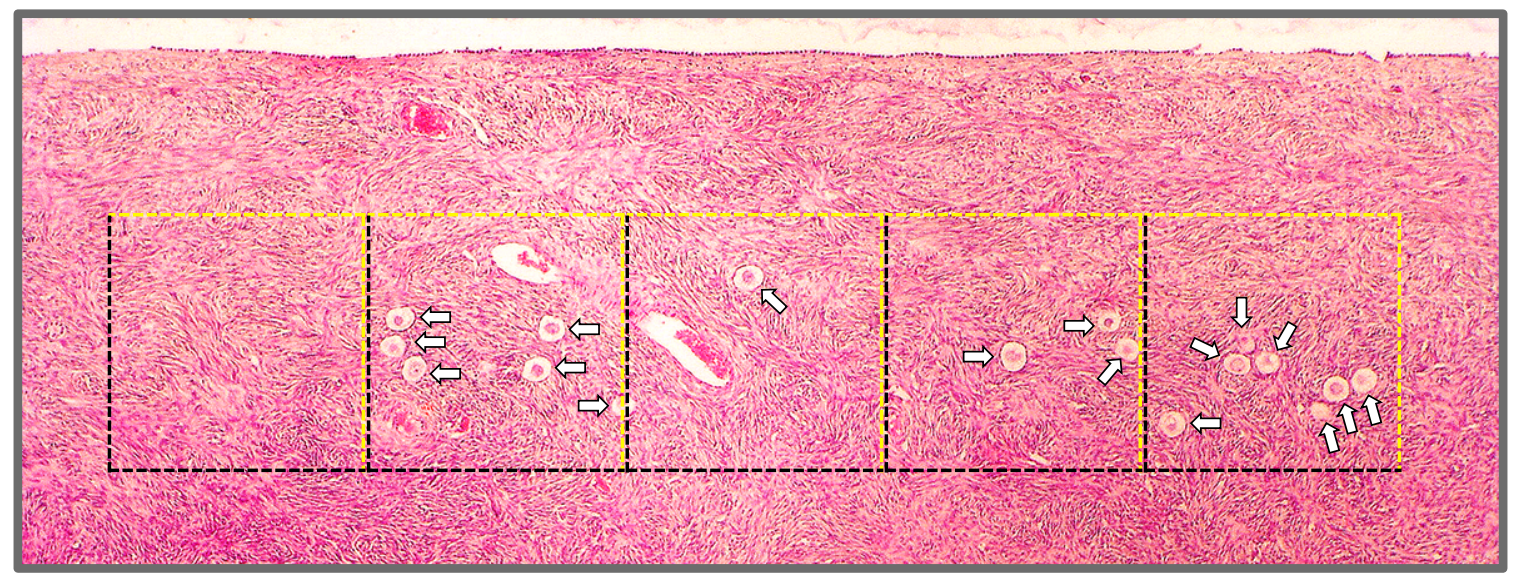

S1 Fig: Scheme of the method applied to obtain the Morisita's index of clustering in the human ovary. A square of $400 \mathrm{x}$ $400 \mu \mathrm{m}$ was displaced in consecutive fields and the number of resting follicles in each square unit recorded. Follicles that are intercepted by the black line are not counted, whereas those intercepted by the yellow line are considered in the field. In the example, the numbers of follicles in the 5 square units are: $0,6,1,3$, and 7 (denoted by arrows). A total of 50 square units per ovary were scored. 